\title{
Effects of Ozone concentration and relative humidity on secondary organic aerosol formation from reactions of 1,3-butadiene with ozone
}

\author{
Ailing Ren ${ }^{*}, 1, a$, Shanshan Wang ${ }^{1, b}$, Shuo Zhang ${ }^{1}$, Miao Tian ${ }^{1}$, Ruijing Yao ${ }^{1}$, \\ Shuo $\mathrm{Li}^{1}$ and Xuan Zhang ${ }^{1}$ \\ ${ }^{1}$ School of Environmental Science and Engineering, Hebei University of Science \\ and Technology, Hebei Research \& Development Center for Air Pollution \\ Prevention and Control, China. Shijizhuang, 050000, China \\ aemail: ailingr@163.com, bemail:wangshanshan0316@163.com
}

Corresponding Author: Ailing Ren

Keywords: 1,3-butadiene, secondary organic aerosols, ozone concentration, relative humidity.

\begin{abstract}
The formation of secondary organic aerosol products from photo-oxidation of 1,3butadiene and ozone was investigated in static smog chamber. The effects of ozone concentration and relative humidity on the particle formation were studied. Research suggests that with the increase of ozone concentration $(0-50 \mathrm{ppm})$, the particle size of particles larger than $0.7 \mu \mathrm{m}$ accounted for the proportion of the total number of particles increased and the initial stage of the ozone decomposition rate increased. But the increase in ozone concentration has little effect on the total number of particles. Relative humidity of $4 \%$ and $25 \%$ of the experimental data show that in the relative humidity of $25 \%$, the initial stage of the ozone decomposition rate is faster and particle size larger than $0.7 \mu \mathrm{m}$ accounted for a larger proportion of the total number of particles. In the same way, the change in relative humidity has little effect on the total number of particles.
\end{abstract}

\section{Introduction}

1,3-butadiene is made of synthetic rubber, synthetic resin, nylon and other raw materials, is one of the typical volatile organic compounds (VOCs) in a pharmaceutical industry, especially in Hebei province. 1,3-butadiene is hazardous to the environment e.g.water, soil and atmosphere, which is also a carcinogenic substance harmful for our physical and mental health. Secondary organic aerosols (SOA) can be formed via 1,3-butadiene photo-oxidation with $\mathrm{OH}$ radicals, $\mathrm{NO}_{\mathrm{x}}$ radicals, and $\mathrm{O}_{3}$. The conversion process can increase the formation of $\mathrm{SOA}^{[1]}$, and SOA produced by the atmospheric oxidation of volatile organic compounds or intermediate-volatility organic compounds, is believed to affect the climate, human health, and visibility ${ }^{[2,3]}$. To reduce these impacts, control strategies are required to reduce their ambient concentrations, and knowledge of 1,3-butadiene ozone photo-oxidation products is required.

Formaldehyde and acrolein have been observed as significant products during chamber studies of the photo-oxidation of 1,3-butadiene in NOx and air ${ }^{[47}$. The reactivity of 1,3-butadiene with ozone in air is relatively low compared to many other alkenes ${ }^{[8,9]}$. Significant acrolein formation has been observed in the 1,3-butadiene/ozone system, as well as the products formaldehyde, acetaldehyde, propanal, 2-butanone, glyoxal and formic acid ${ }^{[9,10]}$. The formation of secondary organic aerosol at yields of $0.4-0.5 \%$ and having a geometric mean diameter $100 \mathrm{~nm}$ has been observed during indoor environmental chamber experiments on 1.0-2.2 ppm 1,3-butadiene in the presence of 0.5-1.1 $\mathrm{ppm} \mathrm{NO}^{[11]}$.

In this study, the effect of ozone concentration and relative humidity on the SOA yield from the ozone photo-oxygenation of 1,3-butadiene using the self-made indoor smog chamber were investigated. 


\section{Experiment}

The schematic diagram of the smog chamber system was shown in Fig. 1. A static smog chamber was used to study the evolution of 1,3-butadiene and ozone. The smog chamber were made of FEP-Teflon film, was a cubic shape and the total volume was $0.3 \mathrm{~m}^{3}$. A simulated VOCs stream was introduced by mass flow controller. 1,3- butadiene concentration is determined offline by GC (7890A, Agilent, USA) with FID detector, while the relative humidity at $25{ }^{\circ} \mathrm{C}$ and ozone concentration were monitored online by a dew point hydrometer (HH314A, OMEGAETTE, USA) and ozone analyzer (UV-100, Model, USA), respectively. The intensity of UV light to smog chamber was $400 \mu \mathrm{W} / \mathrm{cm}^{2}$ measured by a ultraviolet detector (st-513, sentry, Taiwan).

A particle counter (CW-HPC300, ChinaWay, Shenzhen, China) was used to, a ultraviolet detector (st-513 sentry), and an aerosol generator (9302, TSI, Model, United States).

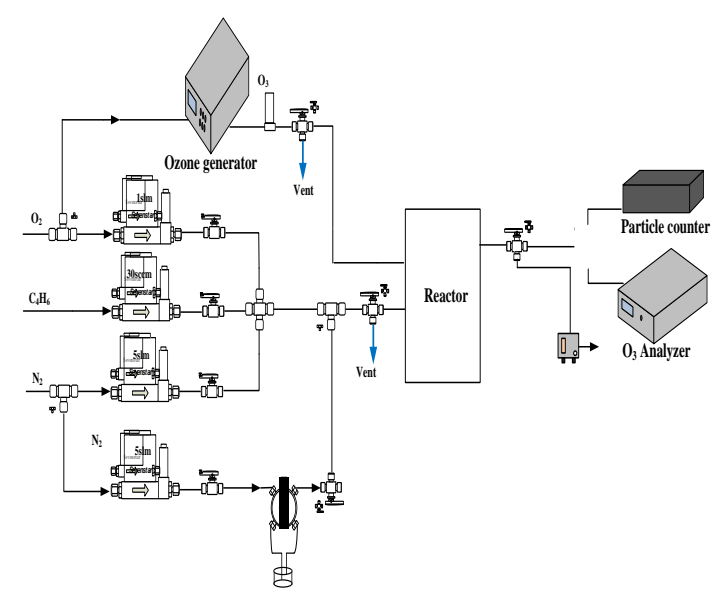

Fig. 1 The schematic diagram of the smog chamber system

\section{Results}

\subsection{Effect of ozone concentration.}

Fig. 2 shows evolution of ozone concentration with UV illumination time in the process of 1,3butadiene ozone photo-oxidation at different ozone concentrations. In general, ozone concentration decreases sharply in the first ten minutes, then decreases slowly over the reaction time and finally all the ozone concentration under different conditions is close to zero. In addition, with increase in ozone concentration, the decline rate at initial stage increases. This result indicats that the increase in ozone concentration accelerates the process of photo-oxidation of 1,3-butadiene and ozone. Fig. 3, Fig. 4 and Fig. 5 show the number of $0.3-0.5 \mu \mathrm{m}, 0.5-0.7 \mu \mathrm{m}$ and greater than $0.7 \mu \mathrm{m}$ particles change with time. Results show when the ozone concentration is $0 \mathrm{ppm}$, the number of particles remains unchanged as the reaction proceeds. So ozone plays an important role in the process of the formation of the secondary organic aerosols by the photo-oxidation decomposition of 1,3-butadiene. Ozone concentration at different conditions, change of the number of particles was almost the same as the reaction proceeds. In 5 minutes before the start of the reaction, a sharp increase in the number of particles. The different is that the particle size between the $0.3-0.5 \mu \mathrm{m}$ and $0.5-0.7 \mu \mathrm{m}$ particle number in the next 5 minutes rapidly decreased and tended to be stable, in 40 minutes later and slowly increased. The particle size of greater than $0.7 \mu \mathrm{m}$ particle number increased dramatically after the change is very slow, tends to be a dynamic balance. The particle size of $0.3-0.5 \mu \mathrm{m}$ and 0.5-0.7 $\mu \mathrm{m}$ decreased with the increase of ozone concentration, while the particle size of the particle size larger than greater than $0.7 \mu \mathrm{m}$ increased with the increase of the concentration of ozone. Fig. 6 shows that there was no significant difference in the total amount of particulate. 


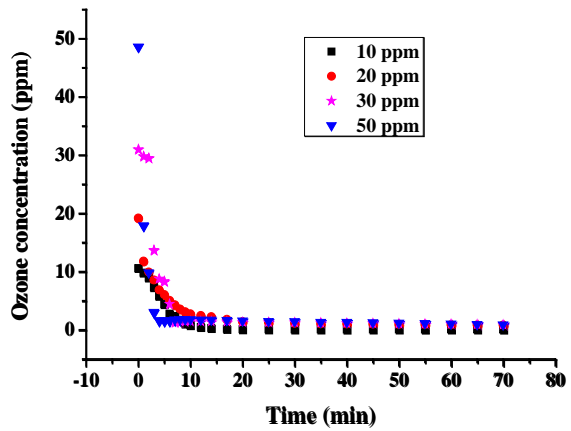

Fig 2. The change of ozone concentration with time

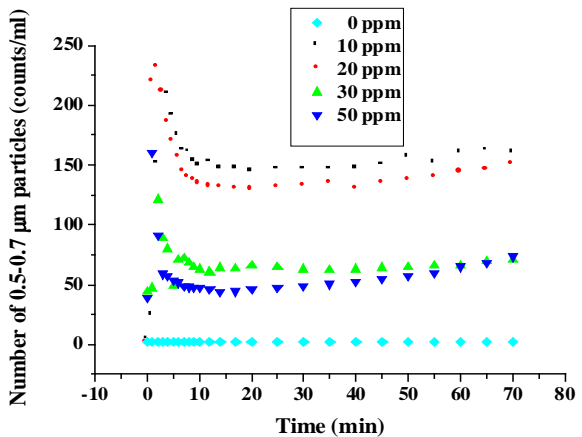

Fig 4 . The change of number of 0.5-0.7 $\mu \mathrm{m}$ particles with time

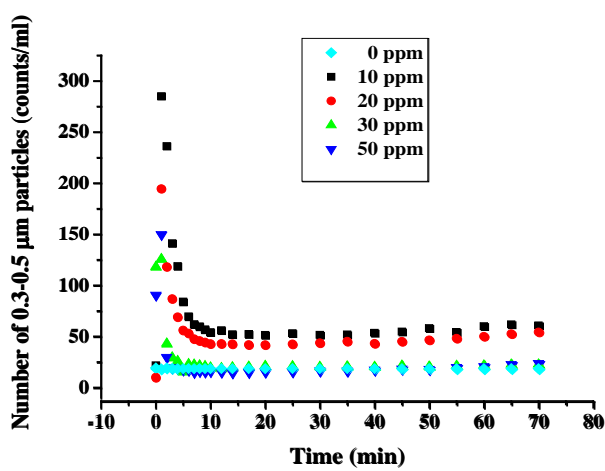

Fig 3. The change of number of 0.3-0.5 $\mu \mathrm{m}$ particles with time

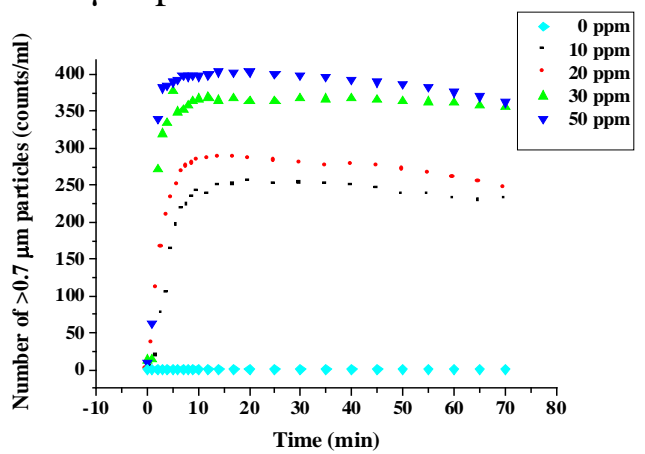

Fig 5. The change of number of $>0.7 \mu \mathrm{m}$ particles with time

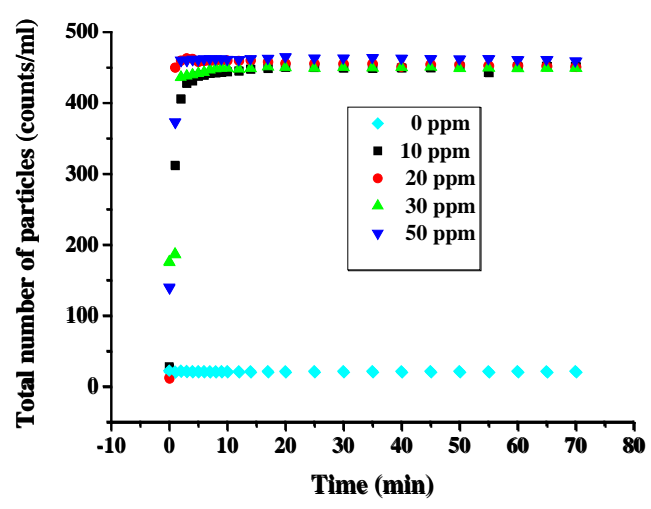

Fig 6. The change of total number of particles with time

\subsection{Effect of relative humidity.}

The effect of relative humidity on the concentration of ozone and the number of particles in the 1,3-butadiene ozone oxidation reaction shown in Fig. 7 and Fig. 8. When the relative humidity was $4 \pm 1 \%$ and $25 \pm 1 \%$, the reaction was started for 20 minutes, the ozone concentration decreased from $20 \mathrm{ppm}$ to $1.3 \mathrm{ppm}$, as the reaction proceeds, the ozone concentration continued to decline slowly until reaching to $0 \mathrm{ppm}$. In comparison, the relative humidity is $4 \%$, the rate of decline in the ozone concentration faster. The total number of particles in the reaction of the beginning of the 3 minutes increased dramatically, followed by a number of increases very slowly, tend to be stable, the relative humidity is not at the same time, the total number of particles is not large.

As shown in Fig. 8, the number of particles increases to a maximum of 5 minutes at the beginning of the reaction, it is interesting that particle size between 0.3-0.5 $\mu \mathrm{m}$ and $0.5-0.7 \mu \mathrm{m}$ particle number then continue to slow increase, but the number of particles greater than $0.7 \mu \mathrm{m}$ diameter has a slow decrease. The results show that the relative humidity has little effect on the total number of particles. 


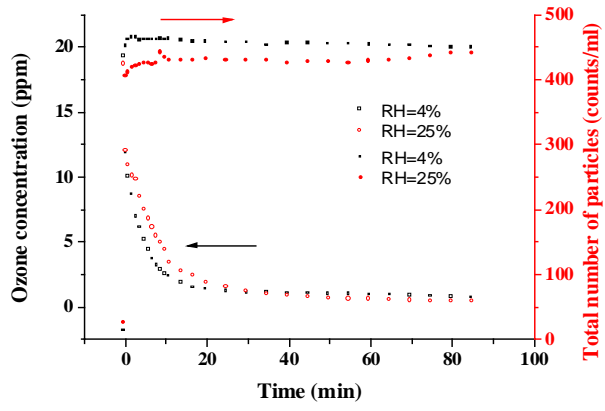

Fig. 7 The change of ozone concentration and total number of particles with time

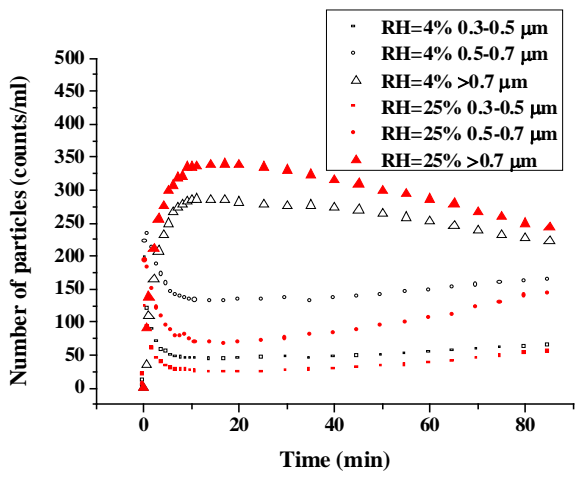

Fig. 8 The change of number of particles with time

\section{Conclusion}

In this study, the effect of ozone concentration and relative humidity on the SOA yield from the ozone photo-oxidation of 1,3-butadiene using the home-made indoor smog chamber were investigated. The SOA yield from 1,3-butadiene ozone photo-oxidation was determined in the absence or presence of ozone. Ozone concentration will not affect the total amount of particulate but will affect the decomposition rate of ozone and particle size distribution. The higher the ozone concentration the more the proportion of particles larger than $0.7 \mu \mathrm{m}$. Similar phenomenon is also observed the effect of different humidity on the ozone oxidation reaction of 1,3-butadiene. It shows that the transformation of particles with small particle size and large particle size promoted by ozone concentration and relative humidity.

\section{Acknowledgement}

This work was financially supported by the National Science technology Support Plan Project of China (Project No. 2014BAC23B04-03) and Foundation of Hebei Province (Project No. 14273712D).

\section{References}

[1]. Liu, X.Y., Zhang, W.J., Wang, Z.Y., et al. Chemical composition and size distribution of secondary organic aerosol formed from the photooxidation of isoprene[J]. Journal of Environmental Sciences. 21(2009): 1525-1531.

[2]. Kei, S.,Satoshi I., Jia-Hua X., et al. Effect of $\mathrm{OH}$ radical scavengers on secondary organic aerosol formation from reactions of isoprene with ozone[J]. Atmospheric Environment. 79(2013): 147-154.

[3]. Hallquist, M., Wenger, J.C., Baltensperger, U., et al. The formation,properties and impact of secondary organic aerosol: current and emerging issues. Atmospheric Chemistry and Physics. 9(2009): 5155-5236.

[4]. Maldotti, A., Chiorboli, C., Bignozzi, C.A., et al. Photooxidation of 1,3-butadiene containing systems: rate constant determination for the reaction of acrolein with $\mathrm{OH}$ radicals. International Journal of Chemical Kinetics. XII(1980): 905-913.

[5]. Tuazon, E.C., Alvaradon, A., Aschmann, S.M., et al. Products of the gas-phase reactions of 1,3butadiene with $\mathrm{OH}$ and $\mathrm{NO}_{3}$ radicals. Environmental Science and Technology. 33(1999): 35863595.

[6]. Liu, X., Jeffries, H.E., Sexton, K.G. Hydroxyl radical and ozone initiated photochemical reactions of 1,3-butadiene. Atmospheric Environment. 33(1999): 3005-3022. 
[7]. Sprengnether, M., Demerjian, K.L., Donahue, N.M., et al. Product analysis of the OH oxidation of isoprene and 1,3-butadiene in the presence of NO. Journal of Geophysical Research. 107(2002): ACH8-1-ACH8-13.

[8]. Atkinson, R., Aschmann, S.M. OH radical production from the gas-phase reactions of $\mathrm{O}_{3}$ with a series of alkenes under atmospheric conditions. Environmental Science and Technology. 27(1993): 1357-1363.

[9]. Kramp, F., Paulson, S.E. The gas phase reaction of ozone with 1,3-butadiene: formation yields of some toxic products. Atmospheric Environment. 3(2000): 35-43.

[10]. Grosjean, D., Grosjean, E., Williams II, E.L. Atmospheric chemistry of olefins: a product study of the ozone-alkene reaction with cyclohexane added to scavenge $\mathrm{OH}$. Environmental Science and Technology. 28(1994): 186-196.

[11]. D.E. Angove, C.J.R. Fookes, R.G. Hynes, et al. The characterisation of secondary organic aerosol formed during the photodecomposition of 1,3-butadiene in air containing nitric oxide[J]. Atmospheric Environment. 40(2006): 4597-4607. 